Núbia da Silva Araújo

Cristiane Teixeira Rodrigues

Márcia Cristina Cury

\section{Helmintos em caixas de areia em creches da cidade de Uberlândia, Minas Gerais}

\section{Helminthes in sandboxes of day care centers of a city in Southeastern Brazil}

\begin{abstract}
RESUMO
O objetivo do estudo foi avaliar a presença de helmintos em caixas de areia de creches públicas e privadas da cidade de Uberlândia, Minas Gerais em 2005. Foram selecionadas 14 creches particulares e 14 públicas que possuíam área de lazer. As coletas foram realizadas em duas estações do ano, uma na seca e a segunda na chuvosa. As amostras foram analisadas pelos métodos de Willis e Baermann. Na primeira coleta 17 (61\%) creches foram positivas para larvas e $14(50 \%)$ para ovos de helmintos e na segunda, em $18(64 \%)$ e $10(36 \%)$, respectivamente. Não foi observada influência da estação climática e da situação socioeconômica das creches.
\end{abstract}

DESCRITORES: Helmintos. Areia. Recreação. Creches. Bem-estar da criança. Saúde da criança.

\begin{abstract}
The objective of the study was to test for helminthes in sandboxes in day care centers in the city of Uberlândia, Southeastern Brazil in 2005. Fourteen private and 14 public day care centers with playgrounds were selected. One collection was carried out during the dry season (June and August), and the second one was in the rainy season (September and November). Samples were tested using Willis and Baermann methods. In the first collection, 17 (61\%) day care centers were positive for helminthes larvae and 14 (50\%) for eggs. In the second collection, $18(64 \%)$ day care centers were positive for larvae and $10(36 \%)$ for eggs. No influence of either season of the year or day care finance condition was seen.
\end{abstract}

KEY WORDS: Helminthes. Sand. Recreation. Child day care centers. Child welfare. Child health.
Laboratório de Parasitologia. Instituto de Ciências Biomédicas. Universidade Federal de Uberlândia, Uberlândia, MG, Brasil

Correspondência | Correspondence:

Márcia Cristina Cury

Laboratório de Parasitologia

Av. Pará, 1720 Bloco 4C Campus Umuarama

38400-902 Uberlândia, MG, Brasil

E-mail: cury@umuarama.ufu.br 


\section{INTRODUÇÃO}

As infecções por helmintos veiculadas pelo solo são freqüentes e relacionadas à deficiência de condições de saneamento e de educação sanitária. Em todo o mundo cerca de 300 milhões de pessoas são acometidas por geo-helmintos, $50 \%$ desse total são crianças em idade escolar. A alta prevalência em crianças é devido a sua maior exposição, principalmente ao freqüentar caixas de areia em praças públicas, escolas e creches. ${ }^{8}$

A contaminação das caixas de areia utilizadas para a recreação infantil constitui grave problema de saúde pública, devido à possibilidade de transmissão de parasitoses como ascaridíase, teníase, ancilostomatíases e, especialmente, larva migrans viceral e larva migrans cutânea. Essas parasitoses podem afetar o equilíbrio nutricional das crianças e gerar complicações: obstrução intestinal, prolapso retal, distúrbios neurológicos e depauperamento físico e mental.

Vários trabalhos têm mostrado altas taxas de contaminação por formas parasitárias nas caixas de recreação. No Brasil, pesquisas realizadas em diferentes regiões relataram a contaminação das areias com ovos e larvas de helmintos e cistos/oocistos de protozoários. ${ }^{6}$

O objetivo do presente trabalho foi analisar a presença de helmintos em caixas de areia nas áreas de recreação infantil de creches públicas e privadas.

\section{MÉTODOS}

Foram selecionadas 28 creches: 14 públicas e 14 privadas localizadas na cidade de Uberlândia, Minas Gerais. As coletas foram realizadas em duas etapas, durante as estações climáticas seca (junho/agosto) e chuvosa (setembro/novembro), de 2005.

Foram obtidas 12 amostras de areia de cada caixa para recreação infantil. As caixas foram divididas por quatro linhas, coletando-se três amostras de cada linha, totalizando-se 150 a 200 gramas de areia por caixa. Este procedimento foi realizado visando-se amostrar toda a caixa. Utilizou-se tubo plástico (tipo PVC, 15 $\mathrm{cm}$ comprimento x $6 \mathrm{~cm}$ diâmetro) introduzido no solo a uma profundidade de $5 \mathrm{~cm}$. As amostras foram armazenadas em sacos plásticos estéreis, identificados e armazenados em caixa de isopor até o momento do processamento.

A identificação e a quantificação dos ovos de helmintos foi realizada pelo método de Willis. Foram realizados quatro testes em quatro sub-amostras, analisadas em lâminas em microscópio óptico nas objetivas de 10x e $40 x$.

Para a recuperação e identificação de larvas foram utilizados $30 \mathrm{~g}$ de areia por amostra, seguindo a metodologia proposta por Baermann. Foram analisadas seis lâminas seriadas para cada amostra sob microscópio óptico na objetiva de 40x.

Foram anotados dados sobre localização, clientela atendida e característica de cada creche (pública ou privada). Responsáveis por cada creche responderam a questionário abordando questões sobre procedência e periodicidade da troca de areia das áreas de recreação.

Os dados obtidos foram analisados pelo teste do quiquadrado com intervalo de confiança $95 \%$ e $\mathrm{p} \leq 0,05$.

A autorização para a realização do estudo nas creches foi obtida mediante a apresentação do projeto às respectivas diretorias.

\section{RESULTADOS}

As creches pesquisadas atendiam em média 90 crianças com faixa etária entre quatro e seis anos. Dessas, 15 (54\%) permitiam a utilização do parque apenas no período vespertino, 9 (32\%) somente no período diurno e $4(14 \%)$ em período integral.

Das 28 creches analisadas na estação seca, 17 (61\%) apresentaram positividade para larvas e $14(50 \%)$ para ovos de helmintos. Na estação chuvosa, a positividade encontrada foi de $18(64 \%)$ e $10(36 \%)$ para larvas e ovos, respectivamente. As diferenças entre as percentagens de ovos e larvas observadas entre as duas coletas não foram significativas.

A freqüência de larvas de parasitos para as estações seca e chuvosa foram respectivamente: $42 \%$ e $9 \%$ para a família Ancylostomatidae; $39 \%$ e $34 \%$ para Strongyloides sp.; $15 \%$ e $64 \%$ para larvas de vida livre e $4 \%$ e $1 \%$ para a família Oxyuridae. Nos mesmos períodos, a freqüência de ovos de helmintos encontrada foi de $88 \%$ e $71 \%$ Ascarididae, $0 \%$ e $29 \%$ para Ancylostomatidae e $3 \%$ e $0 \%$ para Taeniidae, respectivamente.

Ao se comparar o grau de infecção do solo por larvas de helmintos com a natureza das creches, observou-se que no primeiro período de coleta, 7 (41\%) creches públicas e $10(59 \%)$ privadas apresentaram-se positivas. No segundo período, 4 (39\%) públicas e 11 (61\%) privadas, mostraram-se positivas, mas essas diferenças não foram estatisticamente significativas (Tabela).

Também não foram significativas as diferenças para a positividade de ovos nas creches públicas e privadas: $9(64 \%)$ e $5(36 \%)$ na primeira coleta, respectivamente; $4(29 \%)$ e $6(64 \%)$ na segunda, respectivamente (Tabela).

Segundo as respostas dos questionários, a procedência da areia utilizada na recreação era de origem comercial 
Tabela. Positividade de ovos e larvas em áreas de lazer de creches segundo natureza da instituição e estação climática. Uberlândia, MG, 2005.

\begin{tabular}{|c|c|c|c|c|c|c|c|c|c|c|}
\hline \multirow{3}{*}{$\begin{array}{l}\text { Natureza da } \\
\text { Instituição }\end{array}$} & \multicolumn{4}{|c|}{ Ovos } & \multirow{3}{*}{$\begin{array}{l}\text { Total } \\
\text { Creches }\end{array}$} & \multicolumn{5}{|c|}{ Larvas } \\
\hline & \multicolumn{2}{|c|}{ Estação seca } & \multicolumn{2}{|c|}{$\begin{array}{l}\text { Início estação } \\
\text { chuvosa }\end{array}$} & & \multicolumn{2}{|c|}{ Estação seca } & \multicolumn{2}{|c|}{$\begin{array}{l}\text { Início estação } \\
\text { chuvosa }\end{array}$} & \multirow{2}{*}{$\begin{array}{l}\text { Total } \\
\text { Creches }\end{array}$} \\
\hline & Positivo & Negativo & Positivo & Negativo & & Positivo & Negativo & Positivo & Negativo & \\
\hline Pública & $9(64 \%)^{*}$ & $5(36 \%)^{*}$ & $4(29 \%)^{*}$ & $10(71 \%)^{*}$ & 14 & $10(59 \%)^{*}$ & $4(36 \%)^{*}$ & $11(61 \%)^{*}$ & $3(30 \%)^{*}$ & 14 \\
\hline Privada & $5(36 \%)^{*}$ & $9(64 \%)^{*}$ & $6(43 \%)^{*}$ & $8(57 \%)^{*}$ & 14 & $7(41 \%)^{*}$ & $7(64 \%) *$ & $7(39 \%)^{*}$ & $7(70 \%)^{*}$ & 14 \\
\hline Total & 14 & 14 & 10 & 18 & 28 & 17 & 11 & 18 & 10 & 28 \\
\hline
\end{tabular}

* Teste de qui-quadrado, com risco de $5 \%$ (2 = 0,05 e 2 tab=3,84).

em $50 \%$ das creches, $28 \%$ proveniente do depósito municipal e $18 \%$ de origem desconhecida. Quanto à freqüência de troca da areia, $11 \%$ das creches informaram trocá-la trimestralmente, $25 \%$ semestralmente, $21 \%$ anualmente, $14 \%$ não realizam troca e $29 \%$ das creches não responderam a esta pergunta.

Das creches pesquisadas $24(86 \%)$ procuravam impedir o acesso de animais nas áreas de lazer por meio de delimitações do local; 27 (96\%) informaram não protegêlas durante a noite ou em período de chuvas.

\section{DISCUSSÃO}

A prevalência de ovos e larvas de helmintos verificada no presente estudo é similar a de outros países ${ }^{2,6,7}$ e superiores aos apresentados por outros autores no Brasil. ${ }^{1,4,5}$ Esta diferença pode estar relacionada às condições climáticas de Uberlândia. Oge \& $\operatorname{Oge}^{9}(2000)$ relataram que a pluviosidade, movimentação eólica e condições do solo seriam fatores determinantes, para a manutenção e dispersão dos ovos de helmintos.

A ausência de diferenças significativas entre a presença de larvas e ovos de helmintos durante as coletas em estações climáticas distintas corrobora aos relatos de Nunes et $\mathrm{l}^{8}$ (2000), que não observaram haver influência entre estações climáticas no aumento da proporção de larvas e ovos de helmintos.

A quantidade e freqüência semelhantes de ovos e larvas de helmintos observadas em creches públicas e privadas indica que esta característica não é fator determinante para a presença de larvas e ovos de helmintos no solo. A contaminação parece estar relacionada com o manejo da areia da área de recreação.

Chieffi \& $\operatorname{Muller}^{4}$ (1978) alertaram que o fato de a utilização da caixa de areia para recreação, principalmente no turno vespertino e durante os meses mais quentes do ano, favoreceria a viabilidade de ovos de helmintos e potencializaria o risco de contaminação.

O encontro de ovos e ou larvas das famílias Ancylostomatidae, Ascarididae, Taeniidae e do gênero Strongyloides mostra a importância do problema para a saúde pública, pois algumas dessas espécies possuem caráter zoonótico.

A origem da areia e a freqüência de troca em cada instituição podem ser fatores de risco importantes para a contaminação. Os estabelecimentos que comercializam, armazenam e distribuem a areia podem não controlar a sanidade de forma efetiva, não evitando o acesso de animais. Todavia, tal questão não foi pesquisada no presente estudo.

Por sua vez, algumas creches também não controlam adequadamente o acesso de animais, os quais podem contaminar o substrato pela eliminação de fezes infectadas (Lima et $\mathrm{al}^{6}$ 1984).

Entretanto, Araújo et al ${ }^{3}$ (2000) alertam que a simples troca da areia das áreas de recreação é insuficiente para controlar a contaminação por ovos e larvas de helmintos veiculados por cães e gatos. Tal controle só pode ser alcançado cobrindo-se as caixas de areia com lonas durante a noite, conforme proposto por Uga e Kataoka $^{10}$ (1995).

Dessa forma, a contaminação parasitária da areia das áreas de recreação infantil pode estar mais relacionada ao manejo da areia escolhida ou à sua e manutenção do que ao caráter público ou privado da creche e época do ano. Sendo assim, há necessidade de maior controle na qualidade das areias utilizadas, como cobertura para parques infantis, visando minimizar o risco de infecção de crianças por geo-helmintoses. 


\section{REFERÊNCIAS}

1. Alcântara N, Bavia E, Silvão RM, Carvalho E. Environmental contamination by Toxocara sp. eggs in public áreas of Salvador, Bahia state, Brazil. Rev Soc Bras Med Trop. 1989; 22(4):187-90.

2. Alonso JM, Stein M, Bojanich MV. Contamination of soils with eggs of Toxocara in a subtropical city in Argentina. J Helminthol. 2001;75(2):165-8.

3. Araújo FR, Araújo CP, Werneck M, Gordski A. Larva migrans cutânea em crianças de uma escola em área do Centro-Oeste do Brasil. Rev Saude Publ. 2000;34(1):84-5.

4. Chieffi PP, Müller EE. Estudo da variação mensal da contaminação do solo por ovos de Toxocara sp. (Nematoda, Ascaroidea), na zona urbana do município de Londrina Estada do Paraná, Brasil. Rev Inst Adolfo Lutz. 1978;38:13-6.

5. Costa-Cruz JM, Nunes RS, Buso AG. Presença de ovos de Toxocara spp. Em praças públicas da cidade de Uberlândia, MG, Brasil. Rev Inst Med trop S Paulo. 1994;36(1):39-42.
6. Lima WS, Camargo MCV, Guimarães MP. Surto de larva migrans em uma creche de Belo Horizonte, Minas Gerais, Brasil. Rev Inst Med trop S Paulo. 1984;26:122-4.

7. Mukaratirwa S, Taruvinga M. A survey on environmental contamination of suburban parks and playgrounds in Harare, Zimbabwe, with canine helminths of zoonotic significance. I $S$ Afr Vet Assoc. 1999;70(3):129-32.

8. Nunes CM, Pena FC, Negreli GB, Anjo CGS, Nakano $\mathrm{MM}$, Stobbe NS. Ocorrência de larva migrans na areia de áreas de lazer das escolas municipais de ensino infantil, Araçatuba, SP, Brasil. Rev Saude Publ. 2000;34(6):656-8.

9. Oge H, Oge S. Quantitative comparison of various methods for detecting eggs of Toxocara canis in samples of sand. Vet Parasitol. 2000;92(1):75-9.

10. Uga S, Kataoka N. Measures to control Toxocara egg contamination in sandpits of public parks. Am J Trop Med Hyg. 1995;52(1):21-4. 